Article

\title{
Booster or Stumbling Block? The Role of Environmental Regulation in the Coupling Path of Regional Innovation under the Porter Hypothesis
}

\author{
Xin Nie ${ }^{1,2,3}$, Jianxian $\mathrm{Wu}^{1}{ }^{1}$, , Han Wang ${ }^{1,3}$, Lihua Li ${ }^{1}$, Chengdao Huang ${ }^{1}$, Weijuan Li ${ }^{1}$ and Zhuxia Wei ${ }^{1, *}$ \\ 1 School of Public Policy and Management, Guangxi University, No 100, Da Xue Road, Nanning 530004, China; \\ toefl678@gxu.edu.cn (X.N.); jasenwu@alu.gxu.edu.cn (J.W.); hanwang@gxu.edu.cn (H.W.); \\ 2101301029@st.gxu.edu.cn (L.L.); 2101301019@st.gxu.edu.cn (C.H.); 2101301033@st.gxu.edu.cn (W.L.) \\ 2 China Center for Agricultural Policy, Peking University, No 5, Summer Palace Road, Beijing 100871, China \\ 3 Department of City and Regional Planning, University of North Carolina Chapel Hill, New East Hall, \\ Chapel Hill, NC 27599, USA \\ * Correspondence: jingshilw@163.com
}

\section{check for}

updates

Citation: Nie, X.; Wu, J.; Wang, H.;

Li, L.; Huang, C.; Li, W.; Wei, Z.

Booster or Stumbling Block? The

Role of Environmental Regulation in

the Coupling Path of Regional

Innovation under the Porter

Hypothesis. Sustainability 2022, 14,

2876. https://doi.org/10.3390/

su14052876

Academic Editor: Grigorios

L. Kyriakopoulos

Received: 24 December 2021

Accepted: 24 February 2022

Published: 1 March 2022

Publisher's Note: MDPI stays neutral with regard to jurisdictional claims in published maps and institutional affiliations.

Copyright: (c) 2022 by the authors. Licensee MDPI, Basel, Switzerland. This article is an open access article distributed under the terms and conditions of the Creative Commons Attribution (CC BY) license (https:// creativecommons.org/licenses/by/ $4.0 /)$.

\begin{abstract}
In the 2018 Global Environmental Performance Index, China's global air quality rank was fourth from last, indicating a more pronounced conflict between the environment and development compared with other countries. Because of the vastness of China's land area, the development of different regions is imbalanced. The achievement of the stipulated goal to be among the top innovative countries in the world by 2035 not only depends on the economically developed eastern part of China but also on the relatively economically underdeveloped central, western, and northeastern parts. In this context, this paper uses time-varying qualitative comparative analysis to explore how the coupling paths of environmental regulation affect regional innovation. The results show that: (1) In most cases at the overall level of China, the Porter hypothesis is supported, and environmental regulation can play the role of a "booster" and stimulate regional innovation. In a few cases, however, the Porter hypothesis is not supported. (2) The Porter hypothesis is also supported in most cases at the regional level, where environmental regulation is mostly a "booster" for regional innovation in the east, center, west, and northeast. (3) Comparison of regional heterogeneity shows that environmental regulation is more important for stimulating regional innovation in the east than in the center, west, and northeast. This study helps to identify the role of environmental regulation in regional innovation. Moreover, it also helps to understand the emphasis China placed on environmental management during the early stages of its economic development.
\end{abstract}

Keywords: environmental regulation; Porter hypothesis; coupling path; qualitative comparative analysis; QCA; TQCA; configuration; SDGs

\section{Introduction}

Whether environmental regulation can stimulate innovation in developing countries has been one of the hot topics among researchers in resource and environmental economics over the past two decades. Neoclassical economists argued that environmental regulation acts as a cost burden for firms and inhibits innovation [1,2]. However, scholars such as Porter argued that reasonable and appropriate environmental regulation could stimulate firm innovation [3], a view known as the Porter hypothesis or the win-win hypothesis [4]. Since then, scholars have conducted studies testing the validity of the Porter hypothesis at the micro-firm level; however, a consensus has not been reached [5,6]. Chan et al. [7] supported the Porter hypothesis with evidence from firms, showing that environmental pressure promoted corporate green innovation. Tang et al. [8] discovered that environmental regulation negatively impacted the efficiency of green enterprise innovation. In the context of global climate change, strengthening environmental regulation is an important tool to achieve sustainable development [9]. According to the Porter hypothesis, 
environmental regulation facilitates improved economic and environmental performance and promotes corporate innovation [10], achieving a win-win situation for both the economy and the environment, which is the core idea of the Porter hypothesis. Appropriate environmental regulation offsets the losses from environmental regulations by stimulating firm innovation with increased profitability [11,12]. Innovation triggered by strict and flexible environmental regulations will also translate into regional and national competitiveness [13].

Recently, research on the Porter hypothesis has begun to expand onto the regional level. Related research showed that environmental regulation can promote regional innovation and that the Porter hypothesis can be valid at the regional level [14]. It has also been found that the Porter hypothesis is only supported in eastern China, but neither in central nor in western China [15]. In contrast, from carbon emissions trading pilot perspective, Nie et al. [16] found that the Porter effect cannot exist at the regional level in China. In summary, it remains uncertain whether the Porter hypothesis can be applied to China and its different regions, and the mechanisms underlying the pathways toward achieving the Porter hypothesis need to be identified. Furthermore, whether environmental regulation acts as a "booster" or "stumbling block" in the path to regional innovation in the largest developing country also needs to be clarified.

From a practical perspective, in the early stage of industrialization of western developed countries, the contradiction between economic development and environmental protection manifested in a "pollute first, treat later" approach [17]. However, in the past 40 years since the reform and opening up, the Chinese government has elevated environmental issues to the same level of importance as economic development, despite the weak level of industrialization. Prominent examples are the Environmental Protection Law of the People's Republic of China of 1989, the declaration of war on pollution of 2014 [18], and the Central Environmental Protection Inspection of 2016 [19]. In contrast to the western pattern of "pollute first, treat later" in the early stages of economic development, it remains to be seen whether it is effective for the world's largest developing country to weigh the contradiction between environment and development. In order to achieve a win-win between both economic development and environmental governance, this paper provides insight into whether emerging developing countries need to adopt strict environmental regulation in their early stages of industrialization.

In order to address the above questions, this paper explores the causal and complex solutions between environmental regulation and regional innovation by using qualitative comparative analysis (QCA) [20,21]. The main contributions of this study are listed in the following:

- First, this paper shows whether the Porter hypothesis is applicable to the world's largest developing country from a macro-regional perspective. This further enriches the study of the Porter hypothesis at the macro level from a theoretical perspective.

- Secondly, considering causal complexity, with the more applicable research method (time-varying QCA (TQCA)), this paper assesses whether a pattern that differs from "pollute first, treat later" is effective.

- Thirdly, by exploring the pathways to achieve the Porter hypothesis in more and less economically developed regions of China, this paper identifies a remedy for inducing a win-win for both the environment and development.

This paper is organized as follows: Section 2 presents a review of relevant literature. Section 3 presents the research methodology, which focuses on the adaptation of QCA and of TQCA to the research design of this paper. Furthermore, the configuration variables are also presented, and the data is described. Section 4 presents the results of the main empirical analysis of the study, including calibration, necessary condition detection, and coupling path analysis. Section 5 presents regional heterogeneity analysis. Section 6 presents a pertinent discussion, summarizes the paper, suggests countermeasures, and presents future research prospects. 


\section{Literature Review}

Regional innovation is not only the key to transforming economic growth but also an important choice for promoting innovation-driven development. Previous studies on regional innovation can be broadly divided into two aspects: those focusing on the regional innovation system [22-24] and those exploring the relationship between regional innovation and other factors [25]. In this context, a regional innovation system refers to the operating network or mechanism formed by the interaction of innovation subjects based on innovation inputs in a specific geographical area [26]. The improvement of the regional innovation system mainly includes universities, enterprises, the government, and the innovation environment [27]. Many factors affect regional innovation, mainly including market-oriented factors [28], spatial factors [29,30], and industrial factors [31]. With increasing resource and environmental constraints, technological innovation for optimizing industrial structure and energy conservation and emission reduction began to receive increasing attention [32]. It has been shown that technological innovation promotes regional green and sustainable development [33]. Based on the regional innovation environment perspective, Wang et al. [34] showed that the policies of wind power companies largely compensate for the "market failure" in areas with weak innovation environments. Li et al. [35] explored the moderating effect of regional factors on the green development of innovation and found that innovation promoted the green development of the industry. In summary, the above studies explore the impact of technological innovation on the environment from a regional perspective, but whether environmental factors exert an impact on regional innovation remains to be explored. If yes, it should be identified whether this impact promotes or inhibits regional innovation, or whether there is no linkage. Further elucidating the impact of environmental factors on regional innovation provides a useful theoretical contribution.

Since the Porter hypothesis was proposed, academics have mostly explored the linear relationship between environmental regulation and innovation, basically agreeing on the three relationships of promotion, inhibition, and lack of any relationship. Neoclassical economics argues that environmental regulation raises firms' production costs, reduces their competitiveness, and negatively affects their profitability. This view argues that the inflexibility of environmental regulation policies inhibits firm innovation [36]. High spending on pollution abatement because of compliance with environmental regulations reduces firms' innovative activities [37], and the disincentive is especially pronounced in small and medium-sized firms, causing them to choose output reduction rather than increasing technological innovation to achieve abatement goals [38]. However, proponents of the Porter hypothesis argue that the restrictions environmental regulation imposes on pollution emissions have pushed firms towards green transformation, thus increasing the number of green patents and promoting technological progress rather than inhibiting it [39]. As environmental regulation deepens, the increasing technological innovation capacity will offset its cost of reducing pollution emissions and treatment, yielding a compensating effect [40]. Environmental regulation promotes the integration of enterprise cost management and the ascension and adjustment of the industrial structure, which improves profitability [41]. This improves corporate performance and competitiveness in the long run.

Regarding research methods, regression and difference in difference (DID) are commonly used linear analysis tools. For example, based on manufacturing firm data and regression, Zhang [42] showed that green credit environmental regulation policies increased firm green productivity, thus supporting the Porter hypothesis. A similar study using propensity score matching-DID found that the newly revised Environmental Protection Law promotes the profitability of listed companies [41]. DID was also used to assess the effect of China's carbon emissions trading system on green development efficiency and regional carbon equality, the results of which also supported the Porter hypothesis [43]. However, further evidence suggested that the Porter hypothesis was not validated. When using DID method, the impact of China's carbon emissions trading pilot policy on firms' 
green innovation was explored, which was found to significantly inhibit innovation [38]. Nie et al. [16] constructed a quasi-natural experiment using China's carbon emissions trading pilot policy and found that environmental regulation failed to stimulate regional Porter effects.

Considering the complexity and diversity of the real environment, merely adopting linear analysis (as completed by the above-mentioned studies) is insufficient, and therefore, nonlinear analysis with the goal to test the Porter hypothesis began to receive attention. Based on mediation and moderation analyses, environmental regulation on green innovation behavior was investigated, which supported the Porter hypothesis [44]. When using moderation analysis, green innovation was found to enhance the competitive advantage of manufacturing firms, which also supported the Porter hypothesis [45]. When using a dynamic panel, Porter effects were found between governmental green environmental concerns and firms' actual investment [46]. However, it is worth noting that both mediation and moderation analysis or dynamic panel only guarantee local nonlinearity for limited variables (two or three), but not all relevant variables are nonlinearly coupled. From a theory perspective, using more adapted nonlinear research tools can validate and expand the theoretical scope of the Porter hypothesis. From a practical perspective, identifying coupling paths under a nonlinear perspective can meet the needs of real-world policy-making, thus better providing ideas for other developing countries.

In conclusion, previous studies have mainly focused on environmental regulation and firm innovation, while the effects of environmental regulation on regional innovation have rarely been explored. In terms of research methodology, previous studies mainly used regression analysis based on a "net effect" perspective to verify the linear relationship between environmental regulation and firm innovation while ignoring the nonlinear relationship and the coupling mechanism of the Porter hypothesis. In considering these shortcomings, this paper uses TQCA to explore whether the Porter hypothesis is valid in China as a whole and in each region, as well as the coupling path between environmental regulation and regional innovation.

\section{Methods}

\subsection{QCA and Time-Varying $Q C A$}

QCA (also known as configuration analysis) is based on Boolean algebraic set theory. It is both a research method and research paradigm that was invented in the 1980s, incorporating both quantitative and qualitative approaches [47]. The basic concept of QCA is to explore how multiple factors affect the dependent variable under different combinations of conditions from a multi-factor coupling perspective. The core assumption of QCA is the assumption of asymmetry, which enables the analysis of different combinations of causes that lead to the generation of outcomes.

The main reasons why QCA is appropriate for this research are summarized in the following: First, QCA can be effectively used to analyze the multiple concurrent (configuration) effects of both the core explanatory variables and other factors (three to nine factors) acting together on the outcome. This is an advantage over the traditional "net effect" thinking of linear analysis. Second, although previous research methods could also be used to explore how the influencing factors act together on the outcome (e.g., latent class analysis and structural equation modeling), these traditional methods of quantitative analysis cannot effectively identify the interdependence, group coupling, and causal asymmetry among variables. Recently, a paper applying QCA has also appeared in the top international environmental research journal Nature Climate Change [48], indicating that QCA is being recognized by more international researchers.

QCA is generally classified into fuzzy sets QCA, crisp sets QCA, and multi-valued sets QCA. QCA is mostly applied to cross-sectional data, while it is less applied to panel data and time-series data $[49,50]$. To apply QCA to the panel and time-series data, TQCA was developed [51]. TQCA is a collective name for a series of QCAs dealing with time effects, mainly including fixed effects QCA (FEQCA), pooled QCA (PQCA), and time differencing 
QCA (TDQCA). This paper uses FEQCA for empirical analysis to deal with the effects of non-time-varying factors in panel data through fixed effects (i.e., within-group decentering). After processing the time effects, calibration, necessary condition analysis, and coupling path analysis were conducted in fsQCA 3.0 software using fuzzy sets.

\subsection{Configuration Variables}

Figure 1 presents the logical framework constructed by this QCA study, including the core configuration variables of interest, research methodology, causal complexity, and regional heterogeneity. The core configuration variables of interest are environmental regulation and regional innovation. The research methodology is an improved TQCA with a temporal dimension. Causal complexity focuses on the asymmetric combination of pathways through which environmental regulation either promotes or inhibits regional innovation. Regional heterogeneity explores the differences between the traditionally developed (east) and less developed (center, west, and northeast) economies of China.

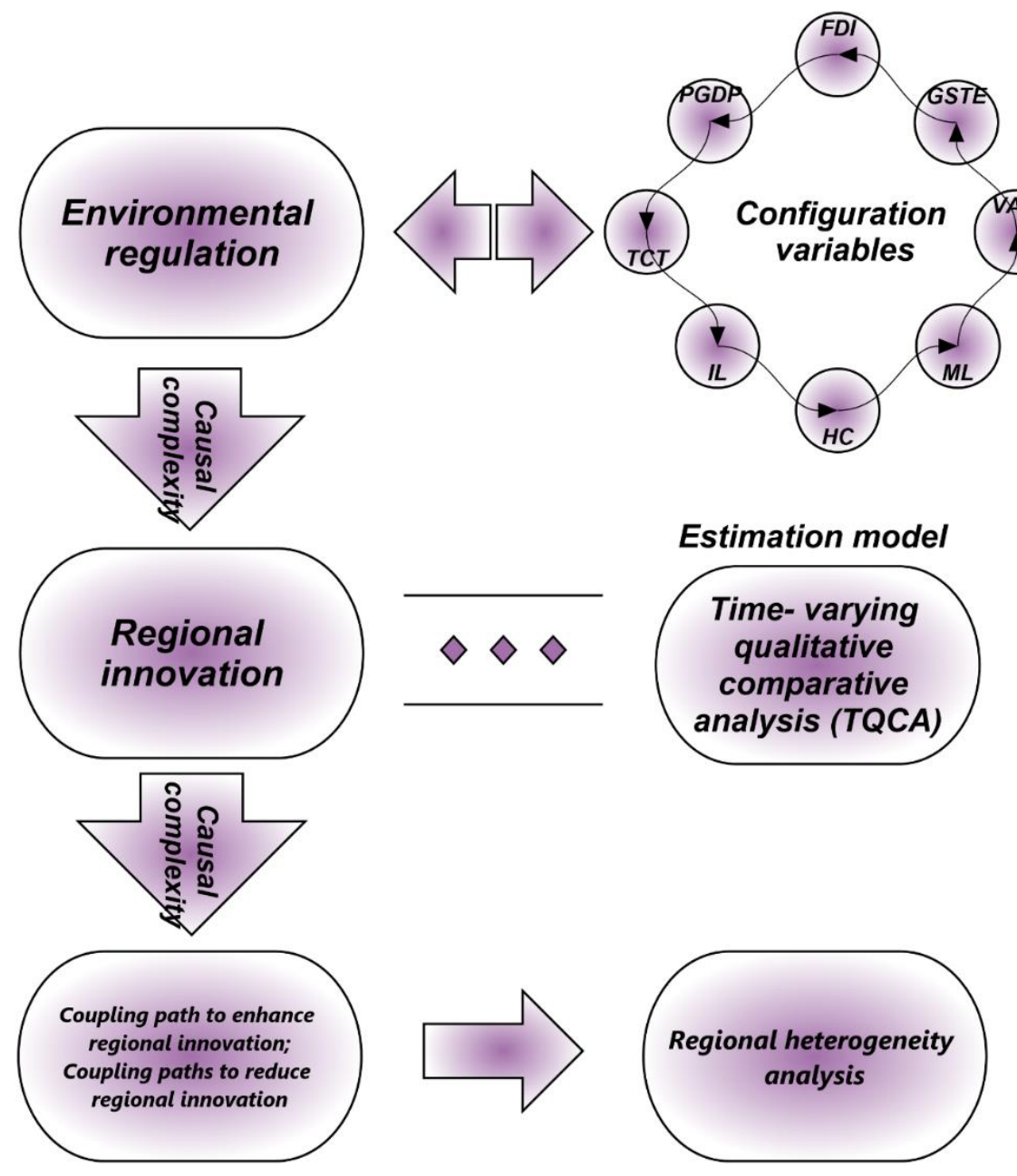

Figure 1. Configuration model for empirical analysis.

The selection of configuration variables depends on two aspects: the realistic context of regional innovation in China and theoretical support from the literature. First, Chinese provincial innovation is the result of a complex multi-factor coupling involving environmental factors, foreign investment, governmental investment, tertiary industry, marketization level, human capital, and infrastructure. Second, by referring to the classical literature on the Porter hypothesis study, configuration variables are specifically selected based on the following. 
Regional innovation (RI): Regional innovation is an important indicator of the output function of knowledge production is patents [52] and has thus become a classic indicator of innovation research [53-56]. Patents provide a basis for regional technological knowledge assessment and are an important tool for analyzing regional technological areas, detecting technologically competitive advantages, and knowledge reorganization [57]. The increase in the number of patents in a region promotes regional innovation and reflects the level of regional innovation [58,59]. Patent-related indicators are also often used in technology specialization strategies for policy formulation [60]. The present paper uses the number of patents granted to industrial firms as a measure of regional innovation. This variable is logarithmically transformed and included in the QCA analysis model, and the remainder of the variables is also transformed logarithmically if not otherwise specified.

Environmental regulation (ER): Investment in pollution treatment projects is necessary to offset the environmental impact caused by industrial pollution emissions [61]. Most academics represent environmental regulation through the costs incurred by environmental treatment; therefore, the volume of pollution treatment investment is widely used as a measure of the intensity of environmental regulation $[15,16]$. The present paper uses the volume of a completed investment in industrial pollution control as a measure of environmental regulation.

Foreign investment in total social fixed assets (FDI): Since the reform and opening up, the opening to the outside world has continually increased. As a response, foreign investment has driven local economic development and progress in science and technology innovation. Empirical evidence showed that foreign investment exerts a significant positive impact on regional innovation [62] and that foreign investment can promote innovation performance in host countries [63]. The increasing level of regional innovation has also further attracted foreign investment [64]. In recent years, foreign investment has contributed to the development of emerging economies [63], and the resulting spatial and knowledge spillovers have provided a dynamic environment for regional innovation [65]. The present paper uses the share of foreign investment of the total social fixed assets as a configuration variable.

Governmental science and technology expenditure (GSTE): Governmental financial spending plays an important role in regional innovation systems [66]. Government financing has promoted independent and external collaborative R\&D [67], especially in emerging industries, where the stimulating effect of government support is greater [68]. Studies have shown that government-funded R\&D activities stimulate producers' innovative behavior [69], improve firms' innovation performance [70], and promote the level of technological innovation in the industry [71,72]. The present paper uses governmental science and technology expenditures as a configuration variable.

The value added to the tertiary industry (VATI): Development of the tertiary industry can expand clean production and optimize the green industrial structure [73]. The structural upgrading of the tertiary industry is conducive to achieving a "win-win" situation in terms of environmental improvement and economic development [74]. This paper uses the value added by the tertiary industry as an indication of the degree of optimization of the industrial structure. In reference to an established empirical study [75], the value added to the tertiary industry is used as a configuration variable.

Marketization level (ML): Market competition drives innovation agents to adjust innovation inputs and change incentive systems; this, in turn, affects the conditions and outputs of regional innovation. The level of marketization positively impacts technological progress, thus promoting industrial synergies and enhancing eco-efficiency [76,77]. In the present paper, the level of marketization is considered as a configuration variable and is measured using the marketization index [78].

Human capital (HC): Human capital is the driving force of all innovation and technological activities and has thus become an important influencing factor of environmental regulation and technological progress [79]. The enhancement of human capital can induce the innovation compensation effect of environmental regulation [80] and even increase 
green total factor productivity [81]. The present paper uses real human capital, as measured by the Central University of Finance and Economics [82], as a configuration variable.

Infrastructure level (IL): Infrastructure development is closely related to economic development and environmental policies [83] and influences the regional transfer of pollutionintensive industries [84]. The present paper uses the length of long-distance fiber optic cable lines in each province as a measure of the level of infrastructure.

Technology contract turnover (TCT): Technology market turnover reflects the activity of enterprise technological innovation and the promotion of regional technological innovation. The transfer and exchange of intellectual property rights between firms is the driving force of regional innovation and increases the probability that innovation is successful [85]. The present paper uses technology contract turnover as a configuration variable.

GDP per capita (PGDP): Empirical evidence suggested that a statistically significant relationship between GDP per capita and innovation has been identified [86]. Therefore, the present paper considers GDP per capita as a configuration variable.

\subsection{Data}

This study is mainly based on balanced panel data from 2003 to 2017 for 30 Chinese provinces and territories (excluding Tibet, Hong Kong, Macau, and Taiwan, because of missing values). Except for human capital data, which was obtained from the China Research Center for Human Capital and Labor Economics, the remainder of the data were obtained from the National Bureau of Statistics of China, the statistical yearbooks of each province and region, and the EPS database. Very few missing values were interpolated using the Monte Carlo method to perform multiple interpolations. Table 1 shows the descriptive statistical information of variables, including observations, means, standard deviations, minimum values, maximum values, and units.

Table 1. Descriptive statistics of variables.

\begin{tabular}{ccccccc}
\hline & $\mathbf{N}$ & Mean & Standard Deviation & Min & Max & Unit \\
\hline RI & 450 & 8.990 & 1.650 & 4.250 & 12.710 & Item \\
ER & 450 & 2.490 & 1.060 & -1.660 & 4.950 & 100 million yuan \\
FDI & 450 & 4.770 & 1.480 & -1.560 & 7.820 & 100 million yuan \\
GSTE & 450 & 3.360 & 1.270 & -0.020 & 6.710 & 100 million yuan \\
VATI & 450 & 8.280 & 1.100 & 4.930 & 10.780 & 100 million yuan \\
ML & 450 & 1.810 & 0.310 & 0.860 & 2.410 & $\backslash$ \\
HC & 450 & 8.660 & 0.880 & 5.910 & 10.280 & One billion yuan \\
IL & 450 & 9.930 & 0.880 & 6.430 & 11.260 & Kilometer \\
TCT & 450 & 12.880 & 1.790 & 7.540 & 17.620 & Ten thousand yuan \\
PGDP & 450 & 10.230 & 0.730 & 8.190 & 11.770 & Yuan \\
\hline Notes:
\end{tabular}

Notes: All variables are transformed logarithmically.

\section{Results}

\subsection{Calibration}

In QCA analysis, combinations of different independent variables with dependent variables are considered as sets, and each observation has a corresponding affiliation within the set. Calibration refers to the process of assigning affiliations to observations in the set [87]. According to the operational requirements of FEQCA, after the original data had been decentered, three calibration points were selected by direct calibration using fuzzy sets, which are full in at the $75 \%$ quantile, crossover at the $50 \%$ quantile, and full out at the $25 \%$ quantile. These three calibration points were selected based on the data distribution characteristics so that the calibrated data is balanced around the 50th percentile as much as possible. The calibration results for both fully affiliated and fully unaffiliated calibration points shifted up and down by the 5\% quantile are also reported in Table 2. 
Table 2. Calibration table.

\begin{tabular}{cccccccccccc}
\hline & N & Min & Max & $\begin{array}{c}\mathbf{2 0 \%} \\
\text { Quantile }\end{array}$ & $\begin{array}{c}\mathbf{2 5 \%} \\
\text { Quantile }\end{array}$ & $\begin{array}{c}\mathbf{3 0 \%} \\
\text { Quantile }\end{array}$ & $\begin{array}{c}\mathbf{5 0 \%} \\
\text { Quantile }\end{array}$ & $\begin{array}{c}\mathbf{7 0 \%} \\
\text { Quantile }\end{array}$ & $\begin{array}{c}\mathbf{7 5 \%} \% \\
\text { Quantile }\end{array}$ & $\begin{array}{c}\mathbf{8 0} \% \\
\text { Quantile }\end{array}$ \\
\hline RI & 450 & -2.870 & 2.260 & -0.868 & -0.690 & -0.539 & 0.010 & 0.575 & 0.730 & 0.889 \\
ER & 450 & -3.910 & 2.320 & -0.699 & -0.540 & -0.345 & 0.090 & 0.505 & 0.640 & 0.781 \\
FDI & 450 & -4.270 & 2.050 & -0.925 & -0.650 & -0.475 & 0.160 & 0.639 & 0.720 & 0.871 \\
GSTE & 450 & -2.670 & 2.650 & -0.840 & -0.700 & -0.589 & -0.010 & 0.525 & 0.680 & 0.835 \\
VATI & 450 & -3.040 & 2.260 & -0.842 & -0.630 & -0.491 & 0.090 & 0.563 & 0.690 & 0.832 \\
ML & 450 & -3.080 & 1.960 & -0.763 & -0.620 & -0.435 & 0.070 & 0.562 & 0.700 & 0.877 \\
HC & 450 & -3.110 & 1.830 & -0.635 & -0.450 & -0.320 & 0.080 & 0.551 & 0.690 & 0.844 \\
IL & 450 & -3.990 & 1.520 & -0.683 & -0.130 & 0.035 & 0.340 & 0.559 & 0.620 & 0.665 \\
TCT & 450 & -2.990 & 2.650 & -0.778 & -0.620 & -0.469 & 0.050 & 0.469 & 0.590 & 0.814 \\
PGDP & 450 & -2.800 & 2.110 & -0.943 & -0.740 & -0.513 & 0.170 & 0.577 & 0.700 & 0.840 \\
\hline
\end{tabular}

Notes: One. The data in the calibration table are variables after decentering. Two. If the affiliation of the calibrated observations is 0.5 , this means that this part of the data will not be simplified by Boolean algebra. According to the principle of data balance, this part of the data is processed by increasing or decreasing by 0.01 [88]. In this paper, 0.501 was chosen to replace 0.5 according to the characteristics of the data distribution.

\subsection{Necessary Condition Testing}

Consistency and coverage are important terms of the necessary condition test. Consistency refers to the sufficiency of the independent variable for the dependent variable, and coverage refers to the uniqueness of the independent variable for the dependent variable; this is similar to the goodness-of-fit $R^{2}$ measure of the econometric model. The calibrated necessity test showed that both GSTE and VATI exceed the critical value of necessity of 0.9 , as shown in Table 3. This implies that increasing GSTE and VATI may be necessary conditions for enhancing regional innovation. This implies that a bottleneck effect exists in the path of enhancing regional innovation and that regional innovation cannot be enhanced without simultaneously focusing on GSTE and VATI. The necessary conditions for lowering regional innovation are tested, which showed that the decrease in GSTE ( GSTE) and the decrease in VATI ( VATI) are necessary conditions for lowering regional innovation. The bottleneck effect exists for the path of lowering regional innovation.

Table 3. Necessary condition testing.

\begin{tabular}{ccccc}
\hline & \multicolumn{2}{c}{ Enhancing Regional Innovation } & \multicolumn{2}{c}{ Reducing Regional Innovation } \\
\cline { 2 - 5 } & Consistency & Coverage & Consistency & Coverage \\
\hline ER & 0.723 & 0.713 & 0.400 & 0.397 \\
$\sim$ ER & 0.388 & 0.391 & 0.711 & 0.721 \\
FDI & 0.855 & 0.850 & 0.274 & 0.274 \\
$\sim$ FDI & 0.270 & 0.270 & 0.850 & 0.855 \\
GSTE & 0.911 & 0.904 & 0.258 & 0.257 \\
$\sim$ GSTE & 0.251 & 0.252 & 0.904 & 0.911 \\
VATI & 0.923 & 0.915 & 0.253 & 0.252 \\
$\sim$ VATI & 0.245 & 0.246 & 0.915 & 0.923 \\
ML & 0.795 & 0.790 & 0.317 & 0.317 \\
$\sim$ ML & 0.313 & 0.313 & 0.790 & 0.795 \\
HC & 0.845 & 0.838 & 0.295 & 0.294 \\
$\sim$ HC & 0.288 & 0.289 & 0.837 & 0.845 \\
IL & 0.601 & 0.597 & 0.491 & 0.491 \\
$\sim$ IL & 0.488 & 0.488 & 0.597 & 0.601 \\
TCT & 0.842 & 0.834 & 0.285 & 0.284 \\
$\sim$ TCT & 0.278 & 0.279 & 0.834 & 0.841 \\
PGDP & 0.806 & 0.802 & 0.320 & 0.320 \\
$\sim$ PGDP & 0.316 & 0.316 & 0.802 & 0.806
\end{tabular}

Notes: ER indicates high-intensity environmental regulation and $\sim$ ER indicates low-intensity environmental regulation. The remaining variables can be similarly interpreted. 


\subsection{Coupling Path Analysis}

QCA analysis can identify three types of solutions: Complex solutions, parsimonious solutions, and intermediate solutions, each of which represents a coupling path. The specific definitions of the three types of solutions can be found in the classic book on QCA [47]. QCA analysis focuses on intermediate solutions and combines parsimonious solutions to distinguish core conditions from periphery conditions.

A frequency of three was selected in fsQCA 3.0, and at least $75 \%$ of the data were retained. The consistency exceeded 0.8 , resulting in 12 paths to enhance regional innovation, as detailed in Table 4 . The overall consistency was 0.974 , indicating that $97.4 \%$ of all observations in all paths could enhance regional innovation. The total coverage is 0.750 , indicating that among all paths, the selected variables can explain $75.0 \%$ of the paths that enhance regional innovation. The overall consistency of QCA analysis exceeded the critical value of 0.75 , implying that this QCA analysis is valid.

Table 4. Coupling path to enhance regional innovation.

\begin{tabular}{|c|c|c|c|c|c|c|c|c|c|c|c|c|}
\hline & \multicolumn{12}{|c|}{ Solutions } \\
\hline & 1 & 2 & 3 & 4 & 5 & 6 & 7 & 8 & 9 & 10 & 11 & 12 \\
\hline ER & $\bar{И}$ & & & $\overline{\mathrm{y}}$ & $\overline{\mathrm{y}}$ & $\overline{\mathrm{y}}$ & $\overline{\mathrm{y}}$ & & $\bar{И}$ & $\overline{\mathrm{y}}$ & $\overline{\mathrm{y}}$ & $\overline{\mathrm{y}}$ \\
\hline FDI & $\overline{\mathrm{y}}$ & $\overline{\mathrm{y}}$ & $\overline{\mathrm{y}}$ & & $\overline{\mathrm{y}}$ & $\overline{\mathrm{y}}$ & $\overline{\mathrm{y}}$ & $\overline{\mathrm{y}}$ & $\overline{\mathrm{y}}$ & $\overline{\mathrm{y}}$ & $\overline{\mathrm{U}}$ & $\overline{\mathrm{U}}$ \\
\hline GSTE & & $\overline{\mathrm{y}}$ & $\overline{\mathrm{y}}$ & $\overline{\mathrm{y}}$ & $\overline{\mathrm{y}}$ & $\overline{\mathrm{y}}$ & $\overline{\mathrm{y}}$ & $\overline{\mathrm{y}}$ & $\overline{\mathrm{y}}$ & & & $\overline{\mathrm{y}}$ \\
\hline VATI & & & $\overline{\mathrm{Y}}$ & $\overline{\mathrm{Y}}$ & $\overline{\mathrm{Y}}$ & $\overline{\mathrm{Y}}$ & $\overline{\mathrm{Y}}$ & $\overline{\mathrm{Y}}$ & $\overline{\mathrm{Y}}$ & $\overline{\mathrm{Y}}$ & $\overline{\mathrm{Y}}$ & $\overline{\mathrm{Y}}$ \\
\hline ML & $\overline{\mathrm{Y}}$ & $\overline{\mathrm{Y}}$ & $\overline{\mathrm{y}}$ & $\overline{\mathrm{U}}$ & $\overline{\mathrm{y}}$ & $\overline{\mathrm{y}}$ & & $\overline{\mathrm{y}}$ & $\overline{\mathrm{U}}$ & $\overline{\mathrm{y}}$ & $\overline{\mathrm{U}}$ & $\overline{\mathrm{Y}}$ \\
\hline $\mathrm{HC}$ & $\bar{и}$ & $\overline{\mathrm{U}}$ & $\overline{\mathrm{Y}}$ & $\overline{\mathrm{Y}}$ & $\overline{\mathrm{Y}}$ & $\overline{\mathrm{Y}}$ & & $\overline{\mathrm{Y}}$ & $\overline{\mathrm{Y}}$ & $\overline{\mathrm{Y}}$ & $\overline{\mathrm{Y}}$ & $\overline{\mathrm{U}}$ \\
\hline IL & $\overline{\mathrm{U}}$ & $\overline{\mathrm{U}}$ & $\overline{\mathrm{U}}$ & $\overline{\mathrm{y}}$ & $\overline{\mathrm{y}}$ & & $\overline{\mathrm{y}}$ & & $\overline{\mathrm{y}}$ & $\overline{\mathrm{U}}$ & $\overline{\mathrm{y}}$ & $\overline{\mathrm{y}}$ \\
\hline TCT & $\overline{\mathrm{y}}$ & $\overline{\mathrm{y}}$ & $\overline{\mathrm{Y}}$ & $\overline{\mathrm{y}}$ & & & & $\overline{\mathrm{y}}$ & & $\overline{\mathrm{Y}}$ & $\overline{\mathrm{y}}$ & $\overline{\mathrm{y}}$ \\
\hline PGDP & $\overline{\mathrm{Y}}$ & $\overline{\mathrm{Y}}$ & & & & $\overline{\mathrm{Y}}$ & $\overline{\mathrm{Y}}$ & $\overline{\mathrm{Y}}$ & $\overline{\mathrm{U}}$ & $\overline{\mathrm{U}}$ & $\overline{\mathrm{Y}}$ & $\overline{\mathrm{Y}}$ \\
\hline Raw coverage & 0.104 & 0.122 & 0.308 & 0.153 & 0.369 & 0.449 & 0.369 & 0.527 & 0.080 & 0.093 & 0.098 & 0.044 \\
\hline Unique coverage & 0.016 & 0.012 & 0.004 & 0.019 & 0.022 & 0.018 & 0.014 & 0.016 & 0.011 & 0.007 & 0.003 & 0.005 \\
\hline Consistency & 0.942 & 0.975 & 0.998 & 0.978 & 0.994 & 1.000 & 0.997 & 0.999 & 0.940 & 0.977 & 0.985 & 0.992 \\
\hline $\begin{array}{c}\text { Overall } \\
\text { consistency }\end{array}$ & \multicolumn{12}{|c|}{0.974} \\
\hline Overall coverage & \multicolumn{12}{|c|}{0.750} \\
\hline
\end{tabular}

Notes: 1. $\overline{\mathrm{y}}$ indicates the presence of a core condition; i.e., the higher the strength of this variable, the stronger its contribution to the results. 2. $\bar{И}$ denotes the absence of a core condition, implying that a lower strength of this variable, leads to a stronger contribution to the outcome. 3. $\bar{y}$ indicates the presence of a periphery condition, meaning that the higher the strength of this variable, the stronger the contribution to the outcome; however, this contribution is lower than the contribution from the presence of the core condition $(\overline{\mathrm{Y}}) .4$. $\overline{\mathrm{u}}$ denotes the absence of the periphery condition, meaning that the lower the strength of this variable, the stronger the contribution to the outcome; however, this contribution is lower than the contribution from the absence of the core condition $(\overline{\mathrm{U}})$. Blank spaces indicate "irrelevant.".

\subsection{Analysis of Coupling Path to Enhance Regional Innovation}

As shown in Table 4, 12 coupling paths enhance regional innovation. In solutions 4, $5,6,7,10,11$, and 12 , the increase in the intensity of environmental regulation leads to an increase in regional innovation; therefore, this mechanism of environmental regulation in regional innovation was identified as "booster". In solutions 1 and 9, the decrease in the intensity of environmental regulation leads to an increase in regional innovation; therefore, this mechanism of the role of environmental regulation in regional innovation was identified as "stumbling block". In solutions 2, 3, and 8, the increase in the intensity of environmental regulation is optional for the improvement of regional innovation; therefore, this mechanism of environmental regulation in regional innovation was identified as "irrelevant". This suggests that in most coupling paths, an increase in the intensity of environmental regulation plays the role of "booster" and enhances regional innovation. In most cases, the Porter hypothesis is supported for China as a whole. Since this paper is mainly based on the theoretical framework of the Porter hypothesis, the pathway mechanism of enhancing regional innovation is examined from the perspective of environmental 
regulation. Therefore, according to the presence or absence of environmental regulation as a core or peripheral condition in different paths, a mechanism map of environmental regulation for regional innovation is generated, as shown in Figure 2.

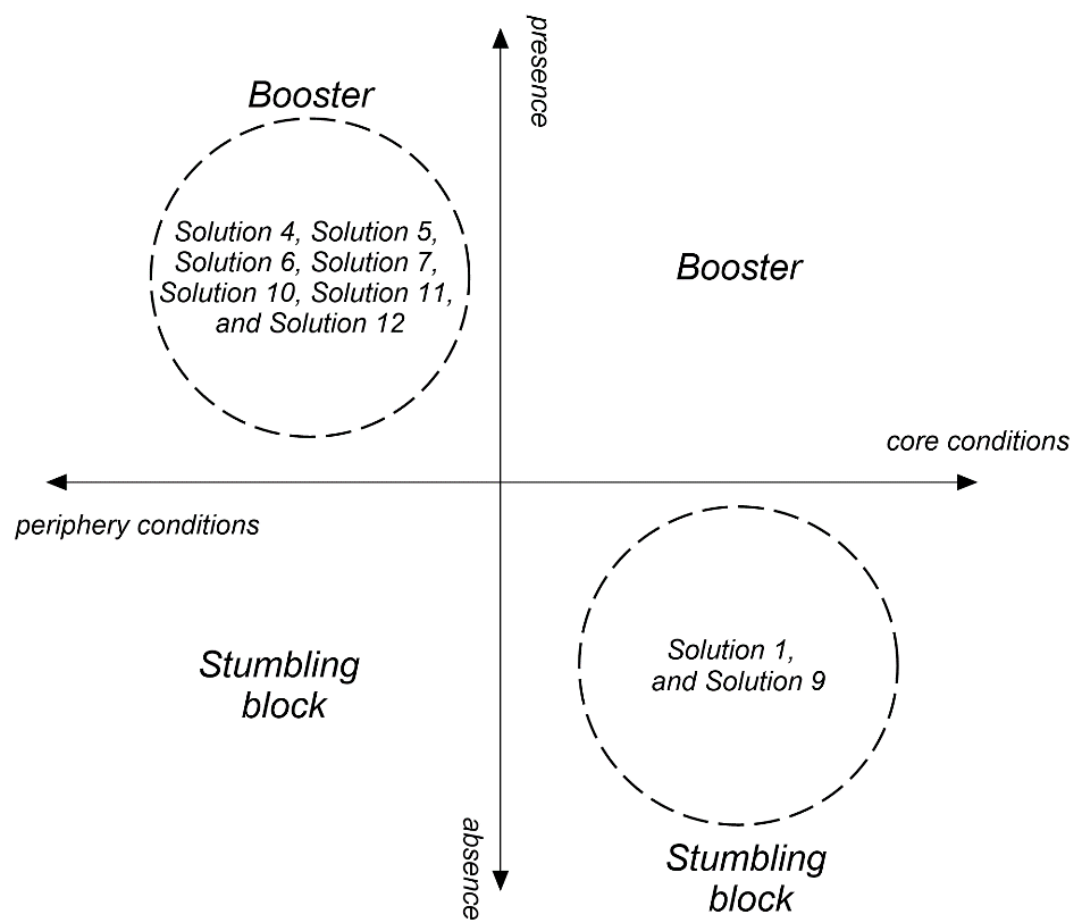

Figure 2. Mechanism map of environmental regulation for regional innovation.

The following solutions are specifically interpreted for the "booster" type. For example, solution 4 indicates that when environmental regulation is high, it is accompanied by very high governmental spending on science and technology, the value added to the tertiary sector, human capital, technology contract turnover, and high levels of infrastructure. Despite the low level of marketization, it is still conducive to enhancing regional innovation. Solution 5 indicates that when environmental regulation is high, a combination of very high foreign investment, governmental science, and technology spending, the value added to the tertiary sector, marketization level, human capital, and a high level of infrastructure are all conducive to enhancing regional innovation. Other solutions are explained similarly.

In summary, environmental regulation can play a role as both "booster", "stumbling block", or be "irrelevant" for the mechanism that triggers the Porter effect. In most cases, the Porter hypothesis is supported for China as a whole, i.e., environmental regulation can promote regional innovation and play the role of "booster". Only in relatively few cases the Porter hypothesis is not supported, which plays the role of "stumbling block". In short, multiple coupling paths of environmental regulation can achieve the role of "booster", and the realization of the Porter hypothesis in China as a whole is characterized by "all roads lead to Rome".

\subsection{Analysis of Coupling Paths to Reduce Regional Innovation}

Based on the asymmetry assumption of QCA, Table 5 shows that 11 coupling paths hinder regional innovation. In solutions 2, 3, 5, 7, and 8, a decrease in the intensity of environmental regulation leads to a decrease in regional innovation. Even in the asymmetry hypothesis, environmental regulation and regional innovation represent the same direction of variation, which reflects the importance of environmental regulation for enhancing regional innovation. Therefore, this mechanism of environmental regulation in regional innovation is identified as a "booster". In solutions 6, 9, 10, and 11, an increase in the intensity of environmental regulation leads to a decrease in regional innovation; as 
environmental regulation plays a role in inhibiting regional innovation, this mechanism of environmental regulation in regional innovation is identified as a "stumbling block". In solutions 1 and 4, the increase in the intensity of environmental regulation is not relevant to the improvement of regional innovation; therefore, the mechanism of environmental regulation in regional innovation is identified as "irrelevant". This suggests that in most coupling paths, a decrease in the intensity of environmental regulation hinders regional innovation to a certain extent, thus reflecting the importance of environmental regulation for promoting regional innovation. In most cases, the Porter hypothesis is supported for China as a whole. The mechanism map of environmental regulation for regional innovation under the asymmetry is shown in Figure 3.

The following solutions are interpreted specifically for the "booster" type. Solution 2 indicates that when environmental regulation is insufficient, foreign investment, governmental science, and technology expenditure, the value added to the tertiary industry, technology contract turnover, GDP per capita, and infrastructure level are insufficient, which decreases regional innovation. Solution 3 indicates that when environmental regulation is insufficient, in addition to foreign investment, governmental science, and technology expenditure, the value added to the tertiary industry, technology contract turnover, human capital, and infrastructure level are also insufficient, which decreases regional innovation. Other solutions are explained similarly.

When considering this asymmetry, the inadequacy of environmental regulation in most paths will lead to a reduction in regional innovation. This shows that environmental regulation is mainly a "booster", and the Porter hypothesis is supported for China as a whole. In a few paths, environmental regulation plays the role of a "stumbling block" or is "irrelevant".

Table 5. Reducing paths to enhance regional innovation.

\begin{tabular}{|c|c|c|c|c|c|c|c|c|c|c|c|}
\hline & \multicolumn{11}{|c|}{ Solutions } \\
\hline & 1 & 2 & 3 & 4 & 5 & 6 & 7 & 8 & 9 & 10 & 11 \\
\hline ER & & $\overline{\bar{u}}$ & $\overline{\bar{u}}$ & & $\overline{\bar{U}}$ & $\overline{\mathrm{y}}$ & $\overline{\bar{u}}$ & $\overline{\mathrm{U}}$ & $\overline{\mathrm{y}}$ & $\overline{\mathrm{y}}$ & $\overline{\mathrm{y}}$ \\
\hline FDI & $\bar{И}$ & $\bar{И}$ & $\bar{И}$ & $\bar{И}$ & $\bar{И}$ & $\bar{И}$ & $\bar{И}$ & $\overline{\mathrm{y}}$ & $\overline{\mathrm{y}}$ & $\bar{И}$ & $\overline{\mathrm{y}}$ \\
\hline GSTE & $\overline{\bar{И}}$ & $\overline{\bar{И}}$ & $\overline{\bar{И}}$ & $\overline{\bar{И}}$ & $\overline{\bar{И}}$ & & $\overline{\bar{И}}$ & $\overline{\bar{И}}$ & $\overline{\bar{U}}$ & $\overline{\bar{U}}$ & $\overline{\bar{U}}$ \\
\hline VATI & $\bar{И}$ & $\bar{И}$ & $\bar{И}$ & $\bar{И}$ & $\bar{И}$ & & $\bar{И}$ & $\bar{И}$ & $\bar{И}$ & $\bar{И}$ & $\bar{И}$ \\
\hline ML & $\bar{И}$ & & & $\bar{И}$ & $\bar{И}$ & $\bar{И}$ & $\bar{И}$ & $\bar{И}$ & $\overline{\mathrm{y}}$ & $\overline{\mathrm{y}}$ & $\overline{\mathrm{y}}$ \\
\hline $\mathrm{HC}$ & $\overline{\mathrm{U}}$ & & $\overline{\mathrm{u}}$ & $\bar{и}$ & $\overline{\mathrm{U}}$ & $\overline{\mathrm{U}}$ & $\overline{\mathrm{y}}$ & $\overline{\mathrm{y}}$ & $\overline{\mathrm{U}}$ & $\overline{\mathrm{y}}$ & $\bar{и}$ \\
\hline IL & & $\overline{\mathrm{U}}$ & $\overline{\mathrm{U}}$ & $\overline{\mathrm{U}}$ & $\overline{\mathrm{y}}$ & $\overline{\mathrm{y}}$ & $\overline{\mathrm{y}}$ & & $\overline{\mathrm{U}}$ & $\overline{\mathrm{y}}$ & $\overline{\mathrm{U}}$ \\
\hline TCT & $\bar{И}$ & $\bar{И}$ & $\bar{И}$ & & & $\bar{И}$ & & $\bar{И}$ & $\bar{И}$ & $\bar{И}$ & $\overline{\mathrm{y}}$ \\
\hline PGDP & & $\overline{\bar{И}}$ & & $\bar{И}$ & & $\overline{\mathrm{y}}$ & $\bar{И}$ & $\bar{И}$ & $\bar{И}$ & $\bar{И}$ & $\overline{\mathrm{y}}$ \\
\hline Raw coverage & 0.551 & 0.325 & 0.333 & 0.287 & 0.263 & 0.101 & 0.108 & 0.082 & 0.057 & 0.071 & 0.049 \\
\hline Unique coverage & 0.061 & 0.021 & 0.007 & 0.013 & 0.010 & 0.034 & 0.013 & 0.014 & 0.011 & 0.018 & 0.016 \\
\hline Consistency & 0.998 & 0.996 & 0.997 & 0.988 & 0.990 & 0.970 & 0.986 & 0.965 & 0.992 & 0.987 & 0.947 \\
\hline $\begin{array}{c}\text { Overall } \\
\text { consistency }\end{array}$ & & & & & & 0.982 & & & & & \\
\hline Overall coverage & & & & & & 0.770 & & & & & \\
\hline
\end{tabular}

Notes: 1. $\overline{\mathrm{Y}}$ indicates the presence of a core condition; i.e., the higher the strength of this variable, the stronger its contribution to the results. 2. $\bar{И}$ denotes the absence of a core condition, implying that a lower strength of this variable, leads to a stronger contribution to the outcome. 3. $\overline{\mathrm{y}}$ indicates the presence of a periphery condition, meaning that the higher the strength of this variable, the stronger the contribution to the outcome; however, this contribution is lower than the contribution from the presence of the core condition $(\overline{\mathrm{Y}}) .4$. $\overline{\mathrm{u}}$ denotes the absence of the periphery condition, meaning that the lower the strength of this variable, the stronger the contribution to the outcome; however, this contribution is lower than the contribution from the absence of the core condition $(\overline{\mathrm{h}})$ Blank spaces indicate "irrelevant.". 


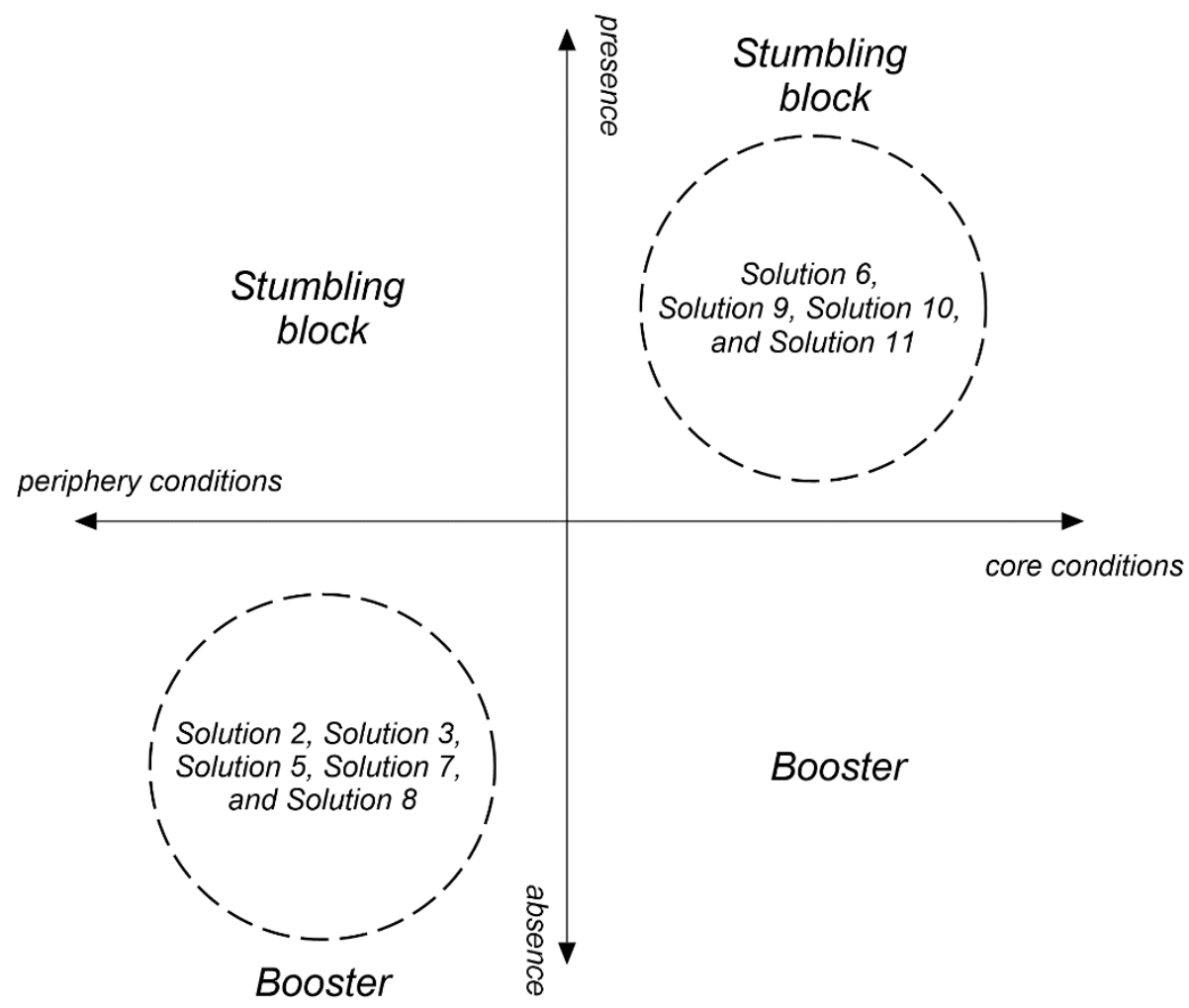

Figure 3. Mechanism map of environmental regulation for regional innovation under the asymmetry assumption.

\subsection{Robustness Checks}

Calibration anchor points were adjusted to test the sensitivity of the results. First, the fully unaffiliated calibration anchor point was adjusted by $25 \%$ to $30 \%$, and the fully affiliated calibration anchor point was adjusted by $75 \%$ to $80 \%$; then, a consistency of 0.8 and a frequency of three were chosen for Boolean algebraic simplification. Following the same steps, the above operation was repeated after shifting the calibration point down by $5 \%$. After adjusting the calibration anchor points, both the number of paths that enhance regional innovation and the number of paths that hinder regional innovation remain unchanged (see Tables S1-S4 in Supplementary Materials). The role of environmental regulation remains unchanged. This implies that the adjustment of calibration anchors does not substantially affect the findings, and the empirical analysis is robust.

\section{Regional Heterogeneity Analysis}

The economic development and resource endowment of each province in China show large heterogeneity [89], and the overall analysis findings may not be applicable for the specific situation of each region; therefore, it is necessary to explore TQCA for each region. In this paper, China is divided into four regions: east, central, west, and northeast (Specific regional divisions are presented in the following: Eastern: Beijing, Tianjin, Hebei, Shanghai, Jiangsu, Zhejiang, Fujian, Shandong, Guangdong, and Hainan. Central: Anhui, Jiangxi, Henan, Hubei, Hunan, and Shanxi. Western: Sichuan, Chongqing, Guizhou, Yunnan, Shaanxi, Gansu, Ningxia, Qinghai, Xinjiang, Inner Mongolia, and Guangxi. Northeast: Heilongjiang, Jilin, and Liaoning).

The results of the TQCA analysis show that there are seven paths that enhance regional innovation in the east, 15 paths that enhance regional innovation in the central region, 11 paths that enhance regional innovation in the west, and 5 paths that enhance regional innovation in the northeast. In order to facilitate the comparison of regional heterogeneity, the "mechanism map of environmental regulation for regional innovation in different regions" (Both Figures 4 and 5 only show the "booster" and "stumbling block" paths, 
while "irrelevant" paths have been omitted.) (see Figure 4) and the "mechanism map of environmental regulation for regional innovation in different regions under the asymmetry" (see Figure 5) were generated. Figure 4 shows that environmental regulation plays more of a "booster" role in the eastern, central, western, and northeastern regions. Figure 5 also demonstrates that environmental regulation plays more of a "booster" role in different regions of China (In Figure 5, the central region is special under the asymmetry assumption. The number of solutions where environmental regulation acts as a "booster" and the number of solutions where it acts as a "stumbling block" is roughly equal. Even the number of solutions where environmental regulation acts as a "booster" (which occurred three times) is one less than the number of conditions where it acts as a "stumbling block" (which occurred four times). This particular phenomenon does not occur in the east, west, and northeast. Based on the results of the positive solution analysis as the main criterion, this study finds that environmental regulation plays more of a "booster" role in the central region).

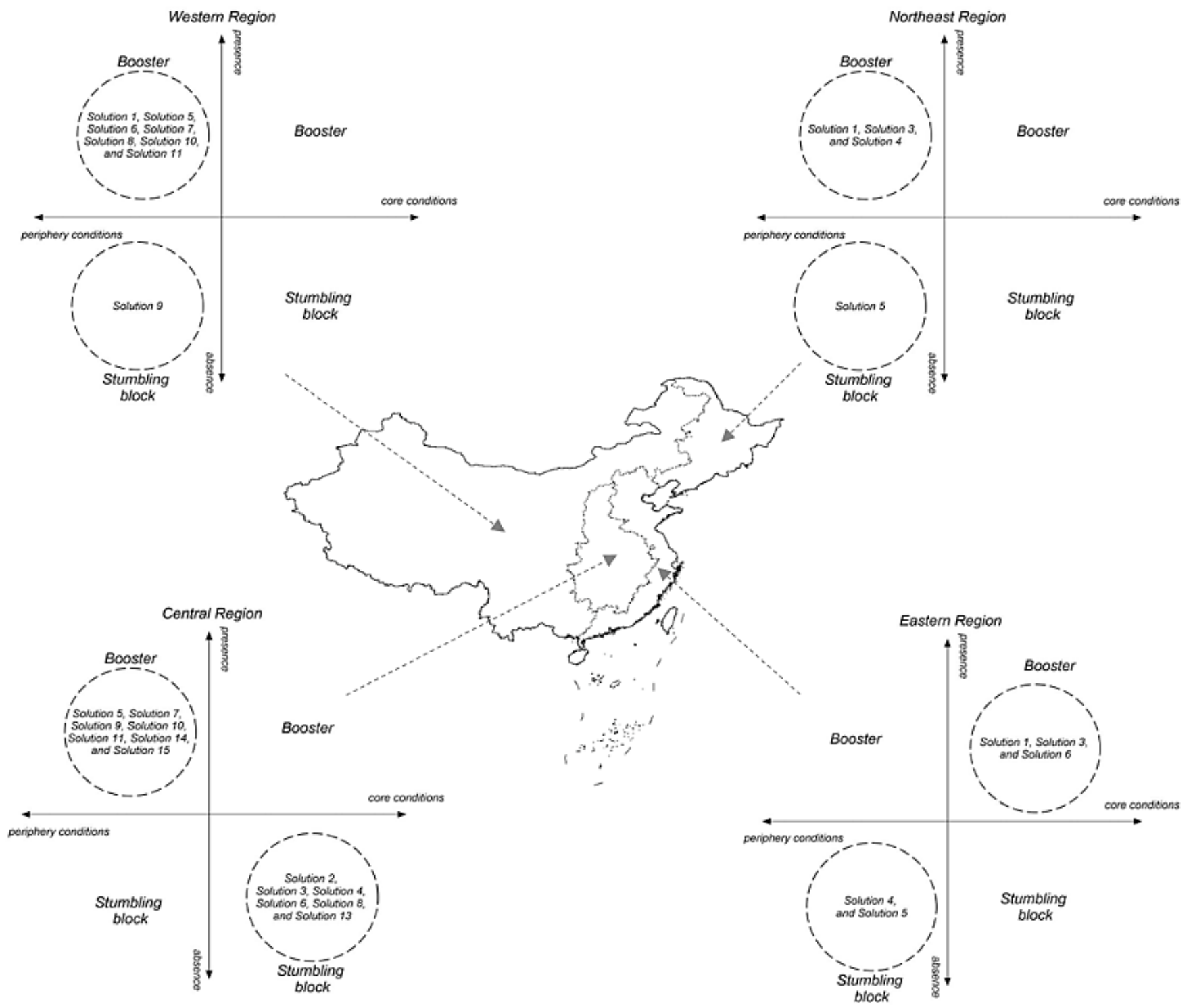

Figure 4. Mechanism map of environmental regulation for regional innovation in different regions. 


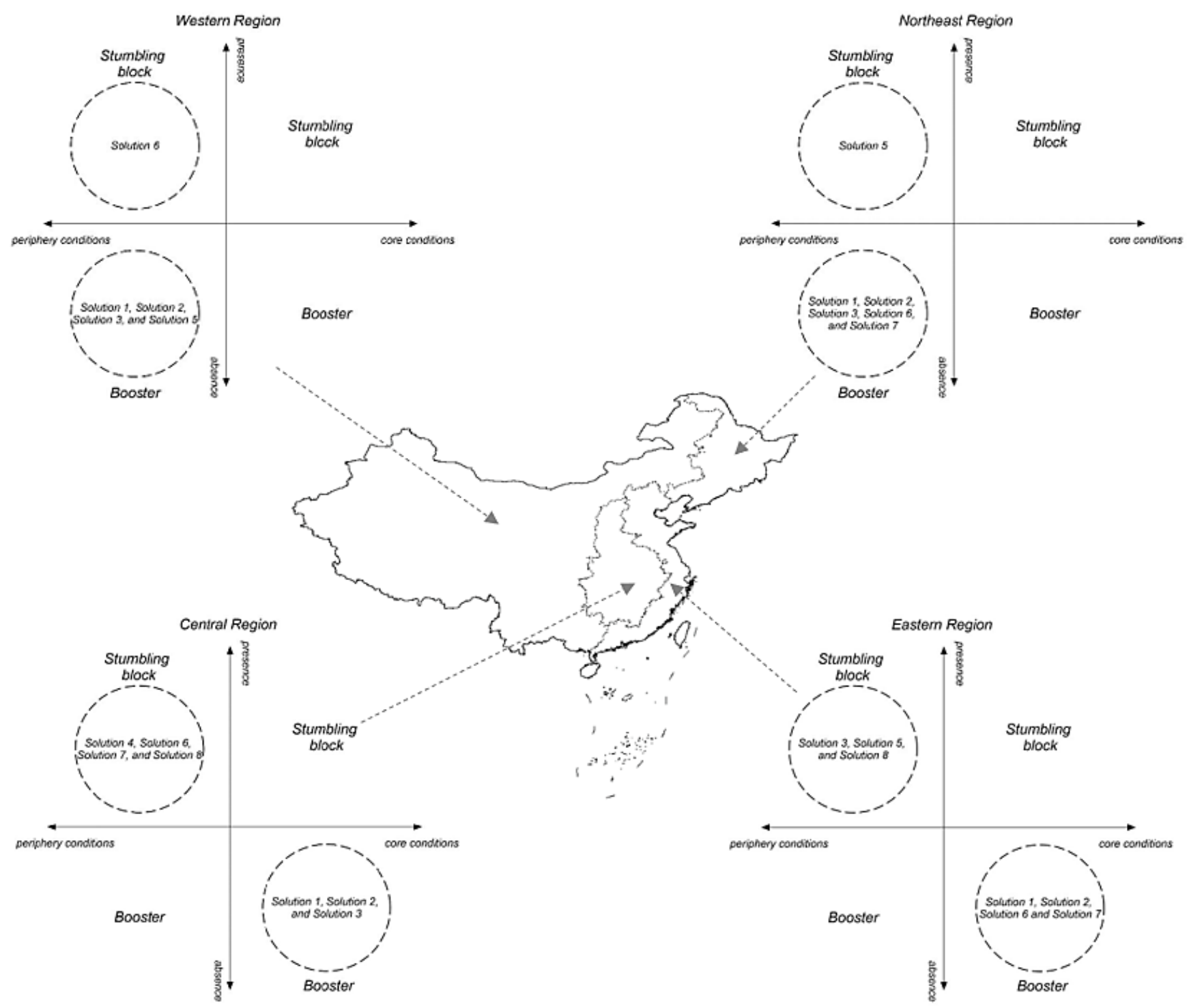

Figure 5. Mechanism map of environmental regulation for regional innovation in different regions under asymmetry.

In the QCA analysis, if a variable is identified as a core condition, it plays a central and dominant role. If a variable is identified as a periphery condition, it only plays a supporting role. Comparison between Figures 4 and 5 shows that environmental regulation appears as both a core condition and a "booster" in the eastern region of Figures 4 and 5. In the central region, environmental regulation is both a core condition and "booster", and only appears in Figure 5. When environmental regulation acts as a "booster" in the west and northeast region, it is not a core condition but a periphery condition in either Figure 4 or Figure 5. This implies that environmental regulation plays a very important role in promoting innovation in the eastern region, while its importance decreases further in the central, western, and northeastern regions.

In summary, the results of this further analysis suggest that environmental regulation plays the role of a "booster" in the mechanism of regional innovation in most cases, whether in the east, center, west, or northeast. In a few cases, however, environmental regulation plays the role of a "stumbling block". In most cases, the Porter hypothesis is supported at the regional level. This empirical result differs from previous studies that concluded that the Porter hypothesis does not apply to western China [15]. Moreover, a comparison of regional heterogeneity showed that environmental regulation is more important for 
stimulating regional innovation in the eastern region than in the central, western, and northeastern regions.

\section{Discussion and Conclusions}

The results of this study are similar to previous findings on the Porter hypothesis, which applies to the world's largest developing country [89]. Deng et al. [90] used superefficient data envelopment analysis to assess the impact of environmental regulation on regional innovation. They concluded that significant consistency exists in the intensity of environmental regulation on regional innovation performance. Environmental regulation promotes regional economic and environmental development by regulating green innovation [91]. An analysis of innovations such as corporate technology and institutions showed that environmental regulation stimulates corporate innovation initiatives and enhances regional competitiveness and sustainable development [6]. An empirical analysis of 274 cities in China also showed that environmental regulation strategies strengthened local environmental regulation lightness, stimulated regional innovation, and reduced pollution transfer [92]. Losacker and Liefner provided a conceptual perspective on regional transformation and regional innovation using a regionalization framework. They found that successful innovation in leading markets within regions gained a competitive advantage [93]. In particular, the traditionally economically developed eastern regions are more likely to stimulate the Porter effect [12]. However, in contrast to previous studies, with the adequate combination of paths, economically average and less developed northeastern, central, and western regions of China also satisfy the preconditions for the Porter hypothesis to hold. This is inconsistent with the finding that the green innovation effect of environmental regulations is significant in the eastern and central regions but not in the western region [94]. Wang and Liu [95] even found evidence indicating that environmental regulation reduces pollution in the east and central regions while increasing it in the west, which contradicts the findings of the present study. Instead, the comparison of regional heterogeneity in this paper suggests that environmental regulation is more important for stimulating regional innovation in the east than in the central, western, and northeastern regions. This also implies that it is important to assess differences in regional development and identify potential areas of policy orientation [96]. This implies that economically developed regions of developing countries should adopt stricter environmental regulations, while less developed or average regions should adopt moderate environmental regulations and avoid one-size-fits-all institutional arrangements.

Green and sustainable development is important for developing countries such as China to achieve the "win-win" goal of environmental governance and innovative development. China is the world's largest developing country. Environmental regulation is not only related to the development of the governmental philosophy of "innovation, coordination, green, openness, and sharing" and the stipulated goal of building an innovative country, it also provides a valuable example for other developing countries that need to deal with environmental and development issues. This, in turn, is related to China's image as a responsible power in the global arena. Based on provincial balanced panel data from 2003-2017, this paper uses TQCA to empirically analyze the coupling paths of how environmental regulation affects regional innovation. The main findings of this paper are summarized in the following:

- First, the Porter hypothesis is supported in most cases at the overall level of China, where environmental regulation can play the role of a "booster" to stimulate regional innovation. In a few cases, however, the Porter hypothesis cannot be supported.

- Second, the Porter hypothesis is also supported in most cases at the regional level, and environmental regulation plays more of a "booster" role for regional innovation in the east, central, west, and northeast.

- Third, a comparison of regional heterogeneity shows that environmental regulation is more important for stimulating regional innovation in the east than in the center, west, and northeast. 
Based on the findings of this study, the following policy insights can be drawn:

- $\quad$ First, China should continue to adhere to strict environmental regulations, implement and enforce the concept of "green water and green mountains are the silver mountain of gold", and use environmental regulation to support regional innovation.

- Second, eastern, central, western, and northeastern China should clearly realize that environmental regulation and regional innovation can coexist and that pollution control and economic development must be pursued in a two-pronged manner.

- Third, eastern China needs to further increase its environmental regulation, while central, western, and northeastern China should moderate environmental regulation.

This paper has the following limitations: This paper focuses on the weak Porter hypothesis [2], which neither includes the strong Porter hypothesis nor the narrow Porter hypothesis while exploring the relationship between environmental regulation and regional innovation. Therefore, follow-up studies could explore the relationship between environmental regulation and regional competitiveness. Although FEQCA is used to overcome the limitation of previous QCA that only applies to cross-sectional data, TQCA can also be used in another way when using panel data: TDQCA analysis [51]. As an emerging research method, QCA offers certain advantages, such as enabling explorations of coupling paths in complex environments. However, QCA cannot answer why observed results occur, and follow-up studies can conduct case studies to explore the underlying mechanism. In addition, this study is limited by data access, and further studies can focus on the prefecture level.

Supplementary Materials: The following supporting information can be downloaded at: https: / /www.mdpi.com/article/10.3390/su14052876/s1, Table S1. Coupling path to enhance regional innovation (Calibration point up 5\%); Table S2. Reducing paths to enhance regional innovation (Calibration point up 5\%); Table S3: Coupling path to enhance regional innovation (Calibration point reduced by 5\%); Table S4. Reducing paths to enhance regional innovation (Calibration point reduced by $5 \%$ ).

Author Contributions: Material preparation, data collection and analysis were performed by J.W. The first draft of the manuscript was written by J.W. and X.N., H.W., L.L., C.H., W.L. and Z.W. commented on previous versions of the manuscript. All authors have read and agreed to the published version of the manuscript.

Funding: This research was funded by National Natural Science Foundation of China, grant number 71763001 and 71973038 and the Social Nature Sciences Foundation of China, grant number 19BGL008.

Institutional Review Board Statement: Not applicable.

Informed Consent Statement: Not applicable.

Data Availability Statement: The data presented in this study are available on request from the corresponding author. The data are not publicly available due to ongoing research on similar topics.

Conflicts of Interest: The authors declare no conflict of interest.

\section{References}

1. Jaffe, A.B. Environmental Regulation and the Competitiveness of U.S. Manufacturing: What Does the Evidence Tell Us? J. Econ. Lit. 1995, 33, 132-163.

2. Jaffe, A.B.; Palmer, K.L. Environmental Regulation and Innovation: A Panel Data Study. Rev. Econ. Stat. 1997, 79, 610-619. [CrossRef]

3. Grubb, M.; Mcdowall, W.; Drummond, P. On order and complexity in innovations systems: Conceptual frameworks for policy mixes in sustainability transitions. Energy Res. Soc. Sci. 2017, 33, 21-34. [CrossRef]

4. Porter, M.; van der Linde, C. Toward A New Conception of the Environment-Competitiveness Relationship. J. Econ. Perspect. 1995, 9, 97-118. [CrossRef]

5. Desrochers, P.; Haight, C.E. Squandered profit opportunities? Some historical perspective on industrial waste and the Porter Hypothesis. Resour. Conserv. Recycl. 2014, 92, 179-189. [CrossRef]

6. Shao, S.; Hu, Z.; Cao, J.; Yang, L.; Guan, D. Environmental Regulation and Enterprise Innovation: A Review. Bus. Strategy Environ. 2020, 29, 1465-1478. [CrossRef] 
7. Chan, H.K.; Yee, R.W.Y.; Dai, J.; Lim, M. The moderating effect of environmental dynamism on green product innovation and performance. Int. J. Prod. Econ. 2016, 181, 384-391. [CrossRef]

8. Tang, K.; Qiu, Y.; Zhou, D. Does command-and-control regulation promote green innovation performance? Evidence from China's industrial enterprises. Sci. Total Environ. 2020, 712, 136362. [CrossRef]

9. $\mathrm{Wu}, \mathrm{R} . ; \mathrm{Lin}, \mathrm{B}$. Environmental regulation and its influence on energy-environmental performance: Evidence on the Porter Hypothesis from China's iron and steel industry. Resour. Conserv. Recycl. 2022, 176, 105954. [CrossRef]

10. Lazzini, S.; Occhipinti, Z.; Parenti, A.; Verona, R. Disentangling economic crisis effects from environmental regulation effects: Implications for sustainable development. Bus. Strategy Environ. 2021, 30, 2332-2353. [CrossRef]

11. Rassier, D.G.; Earnhart, D. Effects of environmental regulation on actual and expected profitability. Ecol. Econ. 2015, 112, 129-140. [CrossRef]

12. Zhao, X.; Sun, B. The influence of Chinese environmental regulation on corporation innovation and competitiveness. J. Clean Prod. 2016, 112, 1528-1536. [CrossRef]

13. Cohen, M.A.; Tubb, A. The Impact of Environmental Regulation on Firm and Country Competitiveness: A Meta-analysis of the Porter Hypothesis. J. Assoc. Environ. Resour. Econ. 2018, 5, 371-399. [CrossRef]

14. Guo, L.; Qu, Y.; Tseng, M. The interaction effects of environmental regulation and technological innovation on regional green growth performance. J. Clean. Prod. 2017, 162, 894-902. [CrossRef]

15. Feng, Y.; Wang, X.; Du, W.; Wu, H.; Wang, J. Effects of environmental regulation and FDI on urban innovation in China: A spatial Durbin econometric analysis. J. Clean. Prod. 2019, 235, 210-224. [CrossRef]

16. Nie, X.; Wu, J.; Chen, Z.; Zhang, A.; Wang, H. Can environmental regulation stimulate the regional Porter effect? Double test from quasi-experiment and dynamic panel data models. J. Clean. Prod. 2021, 314, 128027. [CrossRef]

17. Pegels, A.; Altenburg, T. Latecomer development in a "greening" world: Introduction to the Special Issue. World Dev. 2020, 135, 105084. [CrossRef]

18. Greenstone, M.; He, G.; Li, S.; Zou, E. China's War on Pollution: Evidence from the First Five Years. NBER Work. Pap. 2021. [CrossRef]

19. Zeng, H.; Dong, B.; Zhou, Q.; Jin, Y. The capital market reaction to Central Environmental Protection Inspection: Evidence from China. J. Clean. Prod. 2021, 279, 123486. [CrossRef]

20. de Andrés-Sánchez, J.; Arias-Oliva, M.; Pelegrín-Borondo, J.; Mohammad Almahameed, A.A. The influence of ethical judgements on acceptance and non-acceptance of wearables and insideables: Fuzzy set qualitative comparative analysis. Technol. Soc. 2021, 67, 101689. [CrossRef]

21. Jiao, J.-L.; Zhang, X.-L.; Tang, Y.-S. What factors determine the survival of green innovative enterprises in China?-A method based on fsQCA. Technol. Soc. 2020, 62, 101314. [CrossRef] [PubMed]

22. Wang, J.; Chandra, K.; Du, C.; Ding, W.; Wu, X. Assessing the Potential of Cross-border regional innovation Systems:A case study of the Hong Kong -Shenzhen region. Technol. Soc. 2021, 65, 101557. [CrossRef]

23. Heindl, A.-B.; Liefner, I. The Analytic Hierarchy Process as a methodological contribution to improve regional innovation system research: Explored through comparative research in China. Technol. Soc. 2019, 59, 101197. [CrossRef]

24. Doloreux, D.; Parto, S. Regional innovation systems: Current discourse and unresolved issues. Technol. Soc. 2005, 27, 133-153. [CrossRef]

25. Yang, X.; Zhang, H.; Lin, S.; Zhang, J.; Zeng, J. Does high-speed railway promote regional innovation growth or innovation convergence? Technol. Soc. 2021, 64, 101472. [CrossRef]

26. Cooke, P. Regional innovation systems: Competitive regulation in the new Europe. Geoforum 1992, 23, 365-382. [CrossRef]

27. Buesa, M.; Heijs, J.; Pellitero, M.M.; Baumert, T. Regional Systems of Innovation and the Knowledge Production Function: The Spanish Case. Technovation 2006, 26, 463-472. [CrossRef]

28. Ying, L.M.; Li, M.H.; Yang, J. Agglomeration and driving factors of regional innovation space based on intelligent manufacturing and green economy. Environ. Technol. Innov. 2021, 22, 101398. [CrossRef]

29. Shearmur, R. Innovation, Regions and Proximity: From Neo-Regionalism to Spatial Analysis. Reg. Stud. 2011, 45, 1225-1243. [CrossRef]

30. Rodriguez, M.; Camacho, J.A.; Chica, J. The knowledge-intensive services-regional innovation nexus: A European perspective Serv. Ind. J. 2012, 32, 605-618. [CrossRef]

31. Liu, C.Y.; Gao, X.Y.; Ma, W.L.; Chen, X.T. Research on regional differences and influencing factors of green technology innovation efficiency of China's high-tech industry. J. Comput. Appl. Math. 2020, 369, 112597. [CrossRef]

32. Du, J.; Liu, Y.; Diao, W. Assessing Regional Differences in Green Innovation Efficiency of Industrial Enterprises in China. Int. J. Environ. Res. Public Health 2019, 16, 940. [CrossRef] [PubMed]

33. Chen, L.L.; Zhang, X.D.; He, F.; Yuan, R.S. Regional green development level and its spatial relationship under the constraints of haze in China. J. Clean. Prod. 2019, 210, 376-387. [CrossRef]

34. Wang, X.; Zou, H.; Zheng, Y.; Jiang, Z. How will different types of industry policies and their mixes affect the innovation performance of wind power enterprises? Based on dual perspectives of regional innovation environment and enterprise ownership. J. Environ. Manag. 2019, 251, 109586. [CrossRef]

35. Li, W.; Wang, J.; Chen, R.; Xi, Y.; Liu, S.Q.; Wu, F.; Masoud, M.; Wu, X. Innovation-driven industrial green development: The moderating role of regional factors. J. Clean. Prod. 2019, 222, 344-354. [CrossRef] 
36. Lanoie, P.; Laurent-Lucchetti, J.; Johnstone, N.; Ambec, S. Environmental Policy, Innovation and Performance: New Insights on the Porter Hypothesis. J. Econ. Manag. Strategy 2011, 20, 803-842. [CrossRef]

37. Smirnova, O.; Strumsky, D.; Qualls, A.C. Do federal regulations beget innovation? Legislative policy and the role of executive orders. Energy Policy 2021, 158, 112570. [CrossRef]

38. Chen, Z.; Zhang, X.; Chen, F. Do carbon emission trading schemes stimulate green innovation in enterprises? Evidence from China. Technol. Forecast. Soc. Chang. 2021, 168, 120744. [CrossRef]

39. Yang, Q.; Gao, D.; Song, D.; Li, Y. Environmental regulation, pollution reduction and green innovation: The case of the Chinese Water Ecological Civilization City Pilot policy. Econ. Systems 2021, 45, 100911. [CrossRef]

40. Ouyang, X.; Li, Q.; Du, K. How does environmental regulation promote technological innovations in the industrial sector? Evidence from Chinese provincial panel data. Energy Policy 2020, 139, 111310. [CrossRef]

41. Zhou, D.; Qiu, Y.; Wang, M. Does environmental regulation promote enterprise profitability? Evidence from the implementation of China's newly revised Environmental Protection Law. Econ. Model. 2021, 102, 105585. [CrossRef]

42. Zhang, D.Y. Green credit regulation, induced R\&D and green productivity: Revisiting the Porter Hypothesis. Int. Rev. Finan. Anal. 2021, 75, 101723. [CrossRef]

43. Zhang, S.L.; Wang, Y.; Hao, Y.; Liu, Z.W. Shooting two hawks with one arrow: Could China's emission trading scheme promote green development efficiency and regional carbon equality? Energy Econ. 2021, 101, 105412. [CrossRef]

44. Peng, H.; Shen, N.; Ying, H.Q.; Wang, Q.W. Can environmental regulation directly promote green innovation behavior?-Based on situation of industrial agglomeration. J. Clean. Prod. 2021, 314, 128044. [CrossRef]

45. Tu, Y.; Wu, W. How does green innovation improve enterprises' competitive advantage? The role of organizational learning. Sustain. Prod. Consum. 2021, 26, 504-516. [CrossRef]

46. Farooq, U.; Ahmed, J.; Tabash, M.I.; Anagreh, S.; Subhani, B.H. Nexus between government green environmental concerns and corporate real investment: Empirical evidence from selected Asian economies. J. Clean. Prod. 2021, 314, 128089. [CrossRef]

47. Ragin, C.C. The Comparative Method: Moving Beyond Qualitative and Quantitative Strategies; University of California Press: Berkeley, CA, USA, 2014; p. 216.

48. Rao, N.; Mishra, A.; Prakash, A.; Singh, C.; Qaisrani, A.; Poonacha, P.; Vincent, K.; Bedelian, C. A qualitative comparative analysis of women's agency and adaptive capacity in climate change hotspots in Asia and Africa. Nat. Clim. Chang. 2019, 9, 964-971. [CrossRef]

49. Dușa, A. QCA with R: A Comprehensive Resource; Springer: Berlin/Heidelberg, Germany, 2020.

50. Ragin, C.C.; Strand, S.I. Using Qualitative Comparative Analysis to Study Causal Order: Comment on Caren and Panofsky (2005). Sociol. Methods Res. 2008, 36, 431-441. [CrossRef]

51. Hino, A. Time-Series QCA Studying Temporal Change through Boolean Analysis. Sociol. Theory Methods 2009, $24,247-265$.

52. Rubashkina, Y.; Galeotti, M.; Verdolini, E. Environmental Regulation and Competitiveness: Empirical Evidence on the Porter Hypothesis from European Manufacturing Sectors. Energy Policy 2015, 83, 288-300. [CrossRef]

53. Lee, J.; Veloso, F.; Hounshell, D.A. Linking induced technological change, and environmental regulation: Evidence from patenting in the U.S. auto industry. Res. Policy 2011, 40, 1240-1252. [CrossRef]

54. Acs, Z.J.; Audretsch, D.B. Innovation in Large and Small Firms: An Empirical Analysis. Am. Econ. Rev. 1988, 78, 678-690. [CrossRef]

55. Acs, Z.J.; Anselin, L.; Varga, A. Patents and innovation counts as measures of regional production of new knowledge. Res. Policy 2002, 31, 1069-1085. [CrossRef]

56. Caragliu, A.; Bo, C.D. Smart innovative cities: The impact of Smart City policies on urban innovation. Technol. Forecast. Soc. Chang. 2019, 142, 373-383. [CrossRef]

57. Natalicchio, A.; Mora, L.; Ardito, L.; Petruzzelli, A.M. Evidence-informed decision-making in Smart Specialisation Strategies: A patent-based approach for discovering regional technological capabilities. Reg. Stud. 2021, 1-12. [CrossRef]

58. Fischer, B.B.; Kotsemir, M.; Meissner, D.; Streltsova, E. Patents for evidence-based decision-making and smart specialisation. J. Technol. Transf. 2020, 45, 1748-1774. [CrossRef]

59. D'Adda, D.; Guzzini, E.; Iacobucci, D.; Palloni, R. Is Smart Specialisation Strategy coherent with regional innovative capabilities? Reg. Stud. 2019, 53, 1004-1016. [CrossRef]

60. Pfister, C.; Koomen, M.; Harhoff, D.; Backes-Gellner, U. Regional innovation effects of applied research institutions. Res. Policy 2021, 50, 104197. [CrossRef]

61. Yu, S.; Gao, S.; Sun, H. A dynamic programming model for environmental investment decision-making in coal mining. Appl. Energy 2016, 166, 273-281. [CrossRef]

62. Smith, N.; Thomas, E. Regional conditions and innovation in Russia: The impact of foreign direct investment and absorptive capacity. Reg. Stud. 2017, 51, 1412-1428. [CrossRef]

63. Li, J.; Strange, R.; Ning, L.; Sutherland, D. Outward foreign direct investment and domestic innovation performance: Evidence from China. Int. Bus. Rev. 2016, 25, 1010-1019. [CrossRef]

64. Tang, R.W.; Beer, A. Regional innovation and the retention of foreign direct investment: A place-based approach. Reg. Stud. 2021, 1-14. [CrossRef]

65. Ning, L.T.; Wang, F.; Li, J. Urban innovation, regional externalities of foreign direct investment and industrial agglomeration: Evidence from Chinese cities. Res. Policy 2016, 45, 830-843. [CrossRef] 
66. Guan, J.; Chen, K. Modeling the relative efficiency of national innovation systems. Res. Policy 2012, 41, 102-115. [CrossRef]

67. Engel, D.; Eckl, V.; Rothgang, M. R\&D funding and private R\&D: Empirical evidence on the impact of the leading-edge cluster competition. J. Technol. Transf. 2019, 44, 1720-1743. [CrossRef]

68. Lee, J.; Hwang, J.; Kim, H. Different government support effects on emerging and mature ICT sectors. Technol. Forecast. Soc. Chang. 2022, 174, 121253. [CrossRef]

69. Zhao, X.; Bai, X. How to motivate the producers' green innovation in WEEE recycling in China?-An analysis based on evolutionary game theory. Waste Manag. 2021, 122, 26-35. [CrossRef]

70. Szczygielski, K.; Grabowski, W.; Pamukcu, M.T.; Tandogan, V.S. Does government support for private innovation matter? Firm-level evidence from two catching-up countries. Res. Policy 2017, 46, 219-237. [CrossRef]

71. Luo, G.; Liu, Y.; Zhang, L.; Xu, X.; Guo, Y. Do governmental subsidies improve the financial performance of China's new energy power generation enterprises? Energy 2021, 227, 120432. [CrossRef]

72. Lin, B.; Luan, R. Are government subsidies effective in improving innovation efficiency? Based on the research of China's wind power industry. Sci. Total Environ. 2020, 710, 136339. [CrossRef]

73. Wang, Z.; Jia, H.; Xu, T.; Xu, C. Manufacturing industrial structure and pollutant emission: An empirical study of China. J. Clean. Prod. 2018, 197, 462-471. [CrossRef]

74. Guo, W.; Dai, H.; Liu, X. Impact of different types of environmental regulation on employment scale: An analysis based on perspective of provincial heterogeneity. Environ. Sci. Pollut. Res. 2020, 27, 45699-45711. [CrossRef] [PubMed]

75. Zhou, Q.; Zhang, X.; Shao, Q.; Wang, X. The non-linear effect of environmental regulation on haze pollution: Empirical evidence for 277 Chinese cities during 2002-2010. J. Environ. Manag. 2019, 248, 109274. [CrossRef] [PubMed]

76. Wang, D.; Wan, K.; Yang, J. Ecological efficiency of coal cities in China: Evaluation and influence factors. Nat. Hazards 2019, 95, 363-379. [CrossRef]

77. Zeng, W.; Li, L.; Huang, Y. Industrial collaborative agglomeration, marketization, and green innovation: Evidence from China's provincial panel data. J. Clean. Prod. 2021, 279, 123598. [CrossRef]

78. Fan, G.; Wang, X.; Zhang, L.; Zhu, H.; Xiaolu, W.; Liwen, Z.; Hengpeng, Z. Marketization Index for China's Provinces. Econ. Res. J. 2003, 3, 9-18. (In Chinese)

79. Jiang, Z.; Wang, Z.; Li, Z. The effect of mandatory environmental regulation on innovation performance: Evidence from China. J. Clean. Prod. 2018, 203, 482-491. [CrossRef]

80. Zivin, J.G.; Neidell, M. Environment, health, and human capital. J. Econ. Lit. 2013, 51, 689-730. [CrossRef]

81. Wang, M.; Xu, M.; Ma, S. The effect of the spatial heterogeneity of human capital structure on regional green total factor productivity. Struct. Chang. Econ. Dyn. 2021, 59, 427-441. [CrossRef]

82. Li, H.; Liang, Y.; Fraumeni, B.; Liu, Z.; Wang, X.; Yunling, L.; Barbara, F.; Zhiqiang, L.; Xiaojun, W. China's Human Capital Measurement and Index Construction. Econ. Res. J. 2010, 45, 42-54. (In Chinese)

83. Chowdhury, S.; Zhu, J.; Rasoulkhani, K.; Mostafavi, A.; Jaselskis, E.; Stoa, R.; Li, Q.; Banerjee, S.; Alsharef, A.; Brannen, L. Guidelines for Robust Adaptation to Environmental Regulations in Infrastructure Projects. J. Constr. Eng. Manag. 2020, 146, 04020121. [CrossRef]

84. Zhang, G.; Liu, W.; Duan, H. Environmental regulation policies, local government enforcement and pollution-intensive industry transfer in China. Comput. Ind. Eng. 2020, 148, 106748. [CrossRef]

85. Padilla-Meléndez, A.; Del Aguila-Obra, A.R.; Lockett, N. Shifting sands: Regional perspectives on the role of social capital in supporting open innovation through knowledge transfer and exchange with small and medium-sized enterprises. Int. Small Bus. J. 2012, 31, 296-318. [CrossRef]

86. Li, W.; Gu, Y.; Liu, F.; Li, C. The effect of command-and-control regulation on environmental technological innovation in China: A spatial econometric approach. Environ. Sci. Pollut. Res. 2019, 26, 34789-34800. [CrossRef]

87. Schneider, C.Q.; Wagemann, C. Set-Theoretic Methods for the Social Sciences: A Guide to Qualitative Comparative Analysis; Cambridge University Press: Cambridge, UK, 2012.

88. Crilly, D.; Zollo, M.; Hansen, M.T. Faking it or muddling through? Understanding decoupling in response to stakeholder pressures. Acad. Manag. J. 2012, 55, 1429-1448. [CrossRef]

89. Nie, X.; Wu, J.; Zhang, W.; Zhang, J.; Wang, W.; Wang, Y.; Luo, Y.; Wang, H. Can environmental regulation promote urban innovation in the underdeveloped coastal regions of western China? Mar. Policy 2021, 133, 104709. [CrossRef]

90. Deng, J.; Zhang, N.; Ahmad, F.; Draz, M.U. Local Government Competition, Environmental Regulation Intensity and Regional Innovation Performance: An Empirical Investigation of Chinese Provinces. Int. J. Environ. Res. Public Health 2019, 16, 2130. [CrossRef]

91. Zhang, J.X.; Kang, L.; Li, H.; Ballesteros-Perez, P.; Skitmore, M.; Zuo, J. The impact of environmental regulations on urban Green innovation efficiency: The case of Xi'an. Sustain. Cities Soc. 2020, 57, 102123. [CrossRef]

92. Peng, X. Strategic interaction of environmental regulation and green productivity growth in China: Green innovation or pollution refuge? Sci. Total Environ. 2020, 732, 139200. [CrossRef]

93. Losacker, S.; Liefner, I. Regional lead markets for environmental innovation. Environ. Innov. Soc. Transit. 2020, 37, 120-139. [CrossRef]

94. Li, X.; Hu, Z.; Zhang, Q. Environmental regulation, economic policy uncertainty, and green technology innovation. Clean Technol. Environ. Policy 2021, 23, 2975-2988. [CrossRef] 
95. Wang, H.; Liu, H. Foreign direct investment, environmental regulation, and environmental pollution: An empirical study based on threshold effects for different Chinese regions. Environ. Sci. Pollut. Res. 2019, 26, 5394-5409. [CrossRef] [PubMed]

96. Bresciani, S.; Puertas, R.; Ferraris, A.; Santoro, G. Innovation, environmental sustainability and economic development: DEABootstrap and multilevel analysis to compare two regions. Technol. Forecast. Soc. Chang. 2021, 172, 121040. [CrossRef] 